\title{
Inequality among men in standardised years of potential life lost, 1970-93
}

\author{
David Blane, Frances Drever
}

Information was published last year about the social class distribution of premature deaths in England and Wales during 1991-3. ${ }^{1}$ We analysed these deaths in terms of standardised years of potential life lost, a measure that takes account of the age at death as well as death itself. We considered only men of working age because of the importance of this group to policy. ${ }^{2}$

\section{Subjects, methods, and results}

We used population data from the $10 \%$ sample of each relevant census. This sample is coded to the registrar general's social classification. Only men aged 20-64 years were included because many men outside this age range could not be allocated to a social class. Deaths by age and social class for 1970-2, 1979-80 and 1982-3, and 1991-3 (used in decennial supplements to the census 1,6,15) come from the database at the Office for National Statistics. The categories of cause of death examined are all causes, ischaemic heart disease, malignant neoplasms, and accidents and violence (ICD-9 codes 001-999, 410414, 140-208, and E800-E999).

We used the population of England and Wales in 1981 as the standard to achieve comparability across the three decades. We modified Romeder and McWhinnie's method ${ }^{3}$ to calculate age adjusted rates of years of potential life lost per 1000 population:

$$
\sum\left(65-a_{g}\right) \times \frac{d_{g}}{p_{g}} \times \frac{M_{g}}{M} \times 1000
$$

where $a_{g}=$ mid-age of age group; $d_{g}=$ number of deaths in age and social class group; $\mathrm{p}_{\mathrm{g}}=$ population in age and social class group; $\mathrm{M}_{\mathrm{g}}=$ number of males in England and Wales in 1981 in age group; and $M=$ number of males aged 20-64 in England and Wales in 1981.

The table shows social class differences in standardised years of potential life lost. The ratio of deaths due to all causes between social classes I and V widened from 2.1 in $1970-2$ to 2.9 in $1979-80$ and 1982-3, and to 3.3 in 1991-3. All the main causes of death contributed to this widening, especially ischaemic heart disease, for which the ratio between social classes I and V more than doubled, from 1.5 in 1970-2 to 3.4 in 1991-3. Social class IV became more similar to class III manual in all cause mortality (leaving class $\mathrm{V}$ as a disadvantaged outlier) primarily because of the change in accidents and violence (the number of years lost increased in class III manual and decreased in class IV) and malignant neoplasms (the number of years lost is now lower in class IV than class III manual). By 1991-3 accidents and violence were as important as ischaemic heart disease and malignant neoplasms for each social class, and more important for class V.

\section{Comment}

Measures such as the standardised mortality ratio fail to register fully the extent to which deaths in manual social classes occur at younger ages, thus producing conservative estimates of the size of mortality differentials. In 1991-3, for example, the ratio of death rates in classes I

and $\mathrm{V}$ widened from 2.8 when standardised mortality ratios were used (table $8.2^{1}$ ) to 3.3 when standardised years of potential life lost were used. This raises the estimate of social class V's disadvantage by an amount equivalent to $47 \%$ of social class I's total mortality.

Deaths from accidents and violence tend to occur earlier in adulthood than deaths from ischaemic heart disease and neoplasms; and they occur more often in the manual working class. Accidents and violence consequently contribute substantially to the overall health inequalities among men of working age. The government is committed to reducing health inequalities $^{4}$; tackling accidents and violence offers a potentially prompt strategy for achieving part of this aim.

Contributors: DB and FD jointly had the original idea for the study, carried out the analyses, and wrote the paper.

Funding: None.

Conflict of interest: None

1 Drever F, Whitehead M, eds. Health inequalities. London: Stationery Office, 1997. (Series DS No 15.)

2 Blane D, Davey Smith G, Bartley M. Social class differences in years of potential life lost: size, trends and principal causes. BMJ 1990;301:429-32. 3 Romeder JM, McWhinnie JR. Potential years of life lost between ages 1 and 70: an indicator of premature mortality for health planning. Int J Epidemiol 1977;6:143-51.

4 World Health Organisation. A strategy for health for all: revised targets. Copenhagen: WHO, 1991

(Accepted 18 March 1998)

Annual age adjusted rate of years of potential life lost per 1000 population for principal causes of death in men aged 20-64 in England and Wales for 1970-2, 1979-80 and 1982-3, and 1991-3 (standardised to population of England and Wales 1981)

\begin{tabular}{lccc} 
Social class & $\mathbf{1 9 7 0 - 2}$ & $\mathbf{1 9 7 9 - 8 0 , 1 9 8 2 - 3}$ & $\mathbf{1 9 9 1 - 3}$ \\
\hline All causes of death: & & & \\
\hline I & 48.7 & 36.5 & 28.0 \\
\hline II & 51.9 & 42.2 & 31.6 \\
\hline III non-manual & 65.0 & 53.9 & 45.7 \\
\hline III manual & 66.0 & 58.0 & 50.5 \\
\hline IV & 75.6 & 67.7 & 52.8 \\
\hline V & 103.0 & 105.8 & 93.3 \\
\hline Death from ischaemic heart disease &
\end{tabular}

\begin{tabular}{lccc}
\hline I & 15.3 & 11.1 & 6.1 \\
\hline II & 16.3 & 13.6 & 7.1 \\
\hline III non-manual & 21.2 & 17.9 & 10.6 \\
\hline IV & 19.9 & 18.4 & 12.5 \\
\hline V & 20.5 & 19.7 & 12.8 \\
\hline Death from all malignant neoplasmst: & 22.8 & 26.7 & 20.4 \\
\hline I & 12.5 & 10.0 & \\
\hline II & 12.7 & 10.9 & 9.2 \\
\hline III non-manual & 14.8 & 13.0 & 12.2 \\
\hline III manual & 17.1 & 15.1 & 14.1 \\
\hline IV & 17.9 & 16.2 & 13.6 \\
\hline V & 20.7 & 21.6 & 19.3 \\
\hline Death from accidents and $v i n$
\end{tabular}

\begin{tabular}{|c|c|c|c|}
\hline \multirow{2}{*}{\multicolumn{4}{|c|}{ Death from accidents and violencet: }} \\
\hline & & & \\
\hline I & 8.5 & 7.1 & 5.5 \\
\hline II & 9.1 & 8.1 & 6.4 \\
\hline III non-manual & 9.4 & 9.3 & 9.0 \\
\hline III manual & 10.7 & 11.2 & 11.9 \\
\hline IV & 14.1 & 14.5 & 12.3 \\
\hline V & 24.5 & 27.8 & 26.6 \\
\hline
\end{tabular}

*ICD-9 codes 410-414. †ICD-9 codes 140-208. ¥ICD-9 codes E800-E999.
Department of Behavioural and Cognitive Science, Imperial College School of Medicine, London W6 8RP David Blane, reader in medical sociology

Demography and Health, Office for

National Statistics,

1 Drummond Gate London,

SW1V 2QQ

Frances Drever, statistician

Correspondence to: Dr Blane d.blane@cxwms. ac.uk

\section{BMJ 1998:317:255}

